Guang-Lei Gao, et al., Int. J. of Design \& Nature and Ecodynamics. Vol. 9, No. 2 (2014) 141-148

\title{
COMPARISON OF STAND SPATIAL STRUCTURE IN DIFFERENT PLANTATIONS AND NATURAL FORESTS IN ROCKY MOUNTAIN AREA OF NORTHERN CHINA
}

\author{
GUANG-LEI GAO, GUO-DONG DING, ANG ZHANG, MEI-NA CAO, YUAN-YUAN ZHAO, \\ YAN-FENG BAO, YA-JUAN GUO, MING-HAN YU \& XU LI \\ College of Soil \& Water Conservation, Beijing Forestry University, China.
}

\begin{abstract}
China is the global leader in afforestation efforts to restore degraded forest ecosystems. However, it is difficult for these efforts to completely substitute for natural forests. In order to reveal the differences between plantations and natural forests, we compared stand spatial structure of plantations, mixed plantations, and natural forests by using the mingling degree $\left(M_{i}\right)$, uniform angle index $\left(W_{i}\right)$, and neighborhood comparison $\left(U_{i}\right)$ in the Mulan-Weichang Forestry Administrative region of the rocky mountain area, northern China. The results indicated that natural forests were characterized by varying species composition, individual tree distribution, and competitive relationships, which were more complex than monoculture plantations. Forest management is beneficial to stand spatial structure improvement, resulting in mixed plantations that are closer to natural forests. On this basis, China's forest policy should shift focus from afforestation for area expansion to forest management for ecological improvement.
\end{abstract}

Keywords: Forest restoration, plantation, natural forest, stand spatial structure, forest management.

\section{INTRODUCTION}

The world's total forest area is just over 4 billion ha, which covers $31 \%$ of total terrestrial area and corresponds to an average of 0.6 ha per capita. Although a decrease in deforestation rates and largescale tree planting significantly reduces the net loss of global forest areas, deforestation is still alarmingly and grievously high. In contrast, a report from Asia shows that there has been a net gain of 2.2 million ha forest annually during the period of 2000-2010. Despite continued high rates of net forest loss in many countries in South and Southeast Asia, China's unprecedented afforestation efforts have statistically offset these losses [1]. The Chinese government and international organizations' official bulletins and extensive academic researches show a positive tendency of forest and environment restoration through unprecedented efforts in China [1-4]. For instance, the total forest coverage in China increased from 5.2\% in 1950 to $20.36 \%$ in 2010. Unfortunately, China's environmental sustainability index remains among the lowest in the world $[5,6]$. Even worse, natural forests declined to $30 \%$ of total forest area, while unit area and unit area stocking of natural forests decreased by $32 \%$ [2]. Sometimes, the vast areas of plantations lead to a series of critical, unintended environmental consequences such as water balance damage, desertification expansion, and biodiversity losses [7-9].

Restoration and management of China's forest ecosystems require a deep examination of theories and technologies [10]. However, the reasons for ecological failures are ground and complex; many factors have contributed and their driving forces are often unique and vary widely from situation to situation. In this article, we have only analyzed the differences in stand spatial structure between plantations and natural forests in order to reveal unexpected problems with plantations. Specifically, the objectives of this study were as follow.

1. To characterize the natural forests, mixed plantations, and plantations using the stand spatial structure indicators.

2. To reveal the differences in stand spatial structure between plantations and natural forests.

(C) 2014 WIT Press, www.witpress.com

ISSN: 1755-7437 (paper format), ISSN: 1755-7445 (online), http://journals.witpress.com

DOI: $10.2495 / \mathrm{DNE}-\mathrm{V} 9-\mathrm{N} 2-141-148$ 
3. To guide effective forest restoration in China; this is also instructive to other parts of the world with similar climatic and species conditions (broad-leaved temperate or sub-arctic forests).

\section{STUDY AREA AND METHODS}

\subsection{Study area}

The study area was located in Mulan-Weichang Forestry Administrative region of Hebei Province in the rocky mountain area of northern China $\left(41^{\circ} 50^{\prime} \mathrm{N}, 117^{\circ} 35^{\prime} \mathrm{E} ; 750-1829 \mathrm{~m}\right.$ asl). The area has a continental monsoon climate with an average annual temperature of -1.4 to $4.7^{\circ} \mathrm{C}$ and annual precipitation of 380 to $560 \mathrm{~mm}$, and 1.33 million $\mathrm{hm}^{2}$ are forests, accounting for $84.01 \%$ of the total area. The natural vegetation in this area is mainly broad woody trees platyphylla and Populus davidiana with few conifer species. However, this natural vegetation is now only present in remnants, having been replaced by Larix principis-rupprechtii and Pinus tabulaeformis plantations that cover $51.9 \%$ of the area. Local soil is classified as mountainous brown soil under the natural secondary forest with a relatively thick soil layer, and the natural slope degree is roughly $1 / 150-1 / 350$ [11]. Furthermore, Mulan-Weichang is about $300 \mathrm{~km}$ north of Beijing and lies in the south of Otindag Sandland, one of the four biggest sandlands in China. This area contains the origin of Luan River and provides an ecological shelter for Beijing against sand storms.

\subsection{Field investigation}

Typical L. principis-rupprechtii plantations, mixed plantations, and natural forests were selected and investigated between June and July of 2011 (Table 1). Each of the sites covered an area of $50 \mathrm{~m} \times 50 \mathrm{~m}$. Among them, sites 3 and 4 (mixed plantation) and sites 5 and 6 (plantation) were cut for better growth of individual trees and stand structure improvement in the early spring of 2008 , respectively. The field-based investigation indicators of stand spatial structure were as follows: tree species, quantity, diameter at breast height (DBH), tree height, height of first living branch, crown width, spatial location, and crown closure. We set $3 \mathrm{~cm}$ as the minimum measured diameter.

Table 1: General information of the simple plots in Mulan-Weichang.

\begin{tabular}{|c|c|c|c|c|c|c|c|c|}
\hline \multirow[b]{2}{*}{ Plot } & \multirow[b]{2}{*}{ Species } & \multirow{2}{*}{$\begin{array}{c}\text { Density } \\
\left(\text { stem } \cdot h^{-1}\right)\end{array}$} & \multirow{2}{*}{$\begin{array}{l}\text { Altitude } \\
\text { (m) }\end{array}$} & \multicolumn{2}{|c|}{ Slope } & \multirow{2}{*}{$\begin{array}{c}\text { Forest } \\
\text { age/years }\end{array}$} & \multirow{2}{*}{$\begin{array}{l}\text { Crown } \\
\text { closure }\end{array}$} & \multirow{2}{*}{$\begin{array}{l}\text { Stand } \\
\text { type }\end{array}$} \\
\hline & & & & Aspect & degree $/^{\circ}$ & & & \\
\hline 1 & Bp and Lp & 580 & 1370 & $\mathrm{~N}$ & $19.5^{\circ}$ & various & 0.91 & Natural \\
\hline 2 & Bp and Lp & 722 & 1390 & $\mathrm{~N}$ & $19.5^{\circ}$ & various & 0.96 & forest \\
\hline 3 & $\mathrm{Lp}$ and $\mathrm{Bp}$ & 716 & 1338 & $\mathrm{NE}$ & 21 & 40 & 0.78 & Mixed \\
\hline 4 & Lp and Bp & 944 & 1390 & $\mathrm{NE}$ & 25 & 40 & 0.80 & plantation \\
\hline 5 & Lp & 1567 & 1370 & $\mathrm{~N}$ & 21 & 41 & 0.89 & \\
\hline 6 & $\mathrm{Lp}$ & 744 & 1318 & $\mathrm{~N}$ & 21 & 44 & 0.86 & Plantation \\
\hline
\end{tabular}

Note: Bp represents platyphylla and Lp Larix principis-rupprechtii. 


\subsection{Stand spatial structure analysis}

Forest structure was calculated based on stand spatial structure indicators, which include mingling degree $\left(M_{i}\right)$, uniform angle index $\left(W_{i}\right)$, and neighborhood comparison $\left(U_{i}\right)$ [12-16]. All spatial analysis was conducted using Winkelmass software. Winkelmass software is the stand spatial structure analysis system; it can be used for structural parameter calculation, sampling analysis, and measurement of recovery and reproduction of spatial structure. To eliminate edge effects, we set a $5 \mathrm{~m}$ buffers zone around the investigated stands.

\subsubsection{Mingling degree}

$$
M_{i}=\frac{1}{4} \sum_{j=1}^{n} v_{i j}, M_{i} \in[0,1]
$$

Where $v_{i j}=\left\{\begin{array}{l}1, \text { species }_{j} \neq \text { species }_{i} \\ 0, \text { otherwise }\end{array}\right.$

Mingling degree describes stand spatial isolation using different species proportions in adjacent stand spatial units. $M_{i}$ assumes five possible values $0,0.25,0.5,0.75$, and 1.0 , revealing multi-faceted relationships between reference and neighbor trees in the following categories: zero, weak, middle, strong, and relatively strong mixed degree.

\subsubsection{Uniform angle index}

$$
W_{\mathrm{i}}=\frac{1}{4} \sum_{j=1}^{\mathrm{n}} \mathrm{z}_{i j}, W_{i} \in[0,1]
$$

Where $z_{i j}=\left\{\begin{array}{l}1, a_{j}<a_{0} \\ 0, \text { otherwise }\end{array} ; a_{0}=72^{\circ}\right.$

Uniform angle index represents stand horizontal distribution patterns using adjacent tree positions in adjacent stand spatial units. $W_{i}$ assumes five possible values $0,0.25,0.5,0.75$, and 1.0. Further, when the stand average uniform angle index $(W)$ belong to $[0.475,0.517]$, this indicates a random stand distribution. Accordingly, $W>0.517$ and $W<0.475$ indicate aggregated and random stand distribution, respectively.

\subsubsection{Neighborhood (nearest neighbor) comparison}

$$
U_{\mathrm{i}}=\frac{1}{4} \sum_{\mathrm{j}=1}^{\mathrm{n}} k_{i j}, U_{i} \in[0,1]
$$

Where $k_{i j}=\left\{\begin{array}{l}1, D B H_{j} \geq D B H_{i} \\ 0, \text { otherwise }\end{array}\right.$

Neighborhood (nearest neighbor) comparison indicates stand spatial complexity using the proportion of adjacent trees that are bigger than a reference tree in an adjacent stand spatial unit. $U_{i}$ assumes five possible values $0,0.25,0.5,0.75$, and 1.0 and reveals multiple relationships between reference and neighbor trees in the following categories: competitive advantages, sub-competitive advantages, moderation, competitive disadvantages and extreme competitive disadvantages. Further, we used the DBH-based neighborhood comparison to describe diameter differentiation. 


\section{RESULTS}

\subsection{Mingling degree}

Differences in mingling degree among plantations, mixed plantations, and natural forests are summarized in Table 2. Forest type influenced species spatial isolation of the stand to different degrees. Obviously, natural forests had higher mingling degrees ( 0.500 and 0.464$)$ than plantations and mixed plantations due to their various tree species composition. Generally, natural forests had moderate mingling degrees. In contrast, monoculture plantations had extremely low mingling degrees approaching 0 (0.076 and 0.081), representing little diversity. Mixed plantations showed relatively higher mingling degrees of 0.363 and 0.398 , resulted from unremitting efforts of species composition improvement.

The proportions of individual trees in different mingling degree categories are shown in Fig. 1 . Natural forests had relative homogeneous values of zero (0), weak $(0.25)$, middle $(0.5)$, strong (0.75), and relatively strong (1) mixed individual trees. Moreover, monoculture plantations were characterized by a large proportion of zero mixed individual trees, accounting for three to four times less mixing than that of the natural forests. Compared to monoculture plantations, mixed plantations had a drastic reduction in zero mixed individual trees from $78.8 \%$ and $77.4 \%$ to $29.6 \%$ and $30.5 \%$, although they had little difference in the amount of individual trees in strong mixed conditions. Accordingly, the individual trees in middle and strong mixed conditions significantly increased by approximately $20 \%$.

Table 2: Comparison of stand spatial structure of the simple plots in Mulan-Weichang.

\begin{tabular}{lccc}
\hline Plot & $M_{i}$ & $W_{i}$ & $U_{i}$ \\
\hline 1 & 0.500 & 0.549 & 0.490 \\
2 & 0.464 & 0.512 & 0.487 \\
3 & 0.363 & 0.487 & 0.489 \\
4 & 0.398 & 0.527 & 0.547 \\
5 & 0.076 & 0.481 & 0.462 \\
6 & 0.081 & 0.484 & 0.452 \\
\hline
\end{tabular}

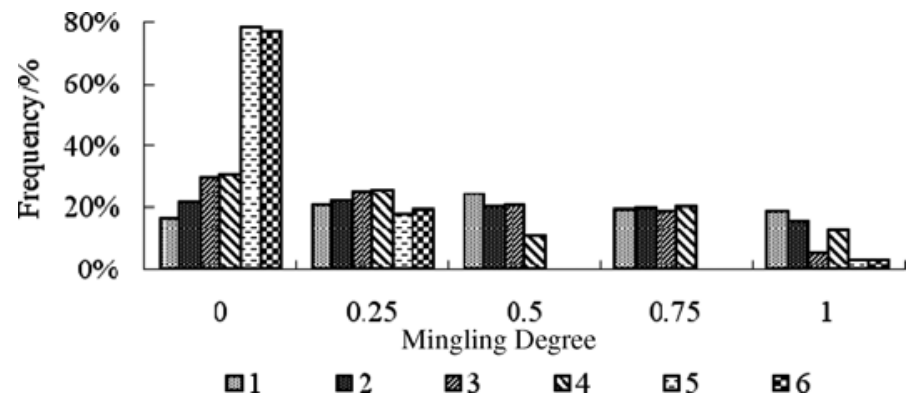

Figure 1: Changes in mingling degree of the simple plots in Mulan-Weichang. 


\subsection{Uniform angle index}

Uniform distribution due to human activities is one of the major characteristics of plantations and is also regarded as one of the major differences between plantation and natural forest. However, in this study, not all the plantations had a uniform distribution, due to mostly improvement thinning efforts (Table 2). Among them, site 3 (mixed plantation), and sites 5 and 6 (plantation) showed random stand spatial distribution with average $W$ values of $0.487,0.481$, and 0.484 , respectively; however, their randomness was low and close to uniform distribution. Further, site $4(W=0.527)$ was characterized by aggregated distribution because of the sprout tillers of B. platyphlla. Like site 4 , site 1 ( $W=0.549$ ) represented an aggregated distribution pattern as well, but its aggregation level was higher than site 4 due to its better seedling regeneration of B. platyphlla. Moreover, as with sites 3 , 5 , and 6 , the natural forest at site 2 exhibited a random stand spatial distribution as well.

For details, the individual tree distribution of uniform angle index in the sample plots was of a unimodal type (Fig. 2). In each site, most of the individual trees, approximately $50 \%-60 \%$, were in random distribution patterns $(W=0.5)$. Furthermore, individual trees had large fluctuation in other distribution patterns. Generally, taking $W=0.5$ as a benchmark, the relation of the two ratios on either side of the benchmark number decides the stand spatial distribution. For instance, in site 1 , individual trees in $W=0$ and $W=0.25(20.9 \%)$ were much lower than those in $W=0.75$ and $W=1$ (27.2), therefore, site 1 showed an aggregated distribution.

\subsection{Neighborhood comparison}

Changes in neighborhood comparison of the simple plots are shown in Table 2 and Fig. 3. Broadly speaking, neighborhood comparison only had a small fluctuation between 0.452 (site 6) and 0.547 (site 4 ) over the different forest types. Therefore, all the forest types were in a moderate state, the competitiveness of monoculture plantations was slightly weaker than in other forests. However, although through neighborhood comparison, it was apparent that there were almost no differences. Taking into consideration individual trees, distributions were not consistent among monoculture plantations, mixed plantations, and natural forests. Therein, the average neighborhood comparison values of natural forests were 0.490 and 0.487 , with approximate frequencies in each competition state. In addition, monoculture plantations had more individual trees at the dominant $(U=0)$ and sub-dominant $(U=0.25)$ levels, but few individual trees at the inferior $(U=0.75)$ and absolutely inferior $(U=1)$ levels. Further, the individual tree distributions of neighborhood comparison in the mixed plantations were between the two abovementioned levels.

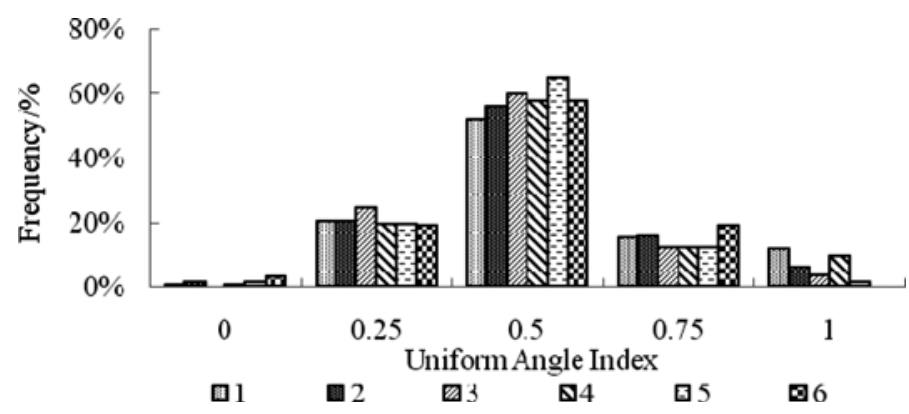

Figure 2: Changes in uniform angle index of the simple plots in Mulan-Weichang. 


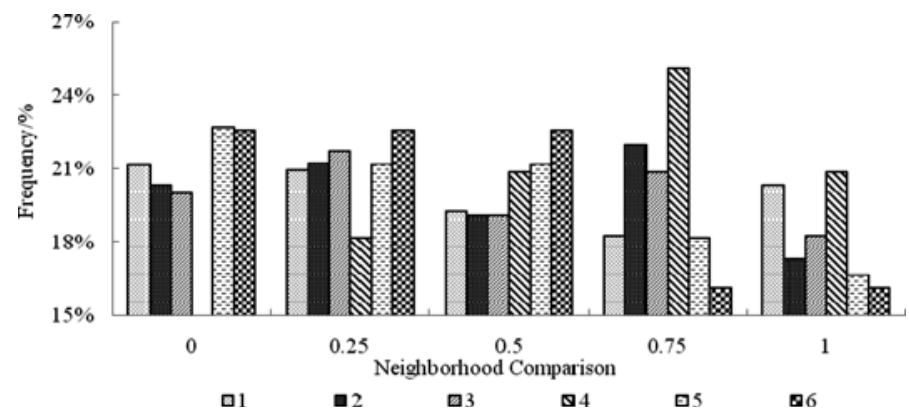

Figure 3: Changes in neighborhood comparison of the simple plots in Mulan-Weichang.

\section{DISCUSSION}

During the last few decades, China has been implementing unprecedented greening efforts to restore degraded forest ecosystems, while simultaneously combating climate change and environmental pollution. However, these monoculture plantations have failed to adequately substitute for natural forests. In former studies, many scholars committed to reveal the differences in forest structures and functions between natural forests and plantations and then generate strategies for degraded plantation improvement. This work demonstrated the differences between plantations and natural forests from the viewpoint of stand spatial structure.

Although there does not seem to be any absolute difference in stand spatial structure between monoculture plantations and natural forests, some overall trends can be deduced from this study. Generally, natural forests are characterized by complex species composition, individual tree distribution, and competitive relationships; monoculture plantations inherently comprise unitary tree species, even distribution, and simple correlations. Further, the stand spatial structure of mixed plantations is in between these two.

Forest structure and functions are closely interconnected and interdependent [11]. In fact, differences between natural forests and plantations are not only in the species composition. Due to the spatial heterogeneity, natural forests have a greatly complicated mass cycles and energy fluxes, affecting the movement and retention of water, solar energy, heat, and air. The ultimate appearance of these differences is the difference in productivity, biodiversity, and soil. Natural forests have stronger abilities in carbon sequestration, soil and water conservation, atmosphere purification and resistance to destruction. Moreover, plantations have simple material and energy fluxes and additionally imply dysfunctional forests [11]. This dysfunction is mainly manifested in low forest quality, vulnerability to diseases and pests, and depletion of some ecological properties.

When forests are lost or degraded, we lose far more than just the trees that they contain but also intangible ecological services [17]. This is one of the most important reasons why plantations fail to completely substitute for natural forests. Thus, greening efforts should focus not only on large scale afforestation for area expansion but also on quality improvement for forest ecosystem restoration. It is commonly believed that natural recovery is still the best way to restore degraded forest ecosystems [18]. However, in many cases, natural recovery is difficult, as it must meet the complex requirements of natural forest ecosystem restoration. In contrast, silvicultural options can modify species composition and structural diversity and have an important potential role in securing ecological functions [14]. True to our study, thinning has significant positive effects on stand spatial structure improvement; forest management is strategic solution for forest ecosystem restoration. 
Species selection is also a very important aspect of reforestation efforts. In this case, broadleaved species are substituted with coniferous species, which adds to the failure to replicate natural conditions. This improved information is essential to providing a firm basis for future policy making on optimal solutions to restore degraded forests in China, as well as the rest of the world.

\section{CONCLUSION}

Using stand spatial analysis, we found significant differences between monoculture plantations and natural forests. This comparison can inform China's forest restoration efforts. It shows that monoculture afforestation and plantations cannot completely replace natural forest ecosystems. With a sharp increase in forest resources during the past 20 years, China's forest policy should be changed to emphasize forest management in order to improve forest quality and ecological services. Native species selection, similar to the ones being replaced, is of the utmost importance.

\section{ACKNOWLEDGEMENTS}

This work was financial supported by the Commonweal Project of State Forestry Administration of P. R. China (200804022A).

\section{REFERENCES}

[1] Food and Agriculture Organization, Global Forest Resources Assessment 2010: Main Report. Food and Agriculture Organization: Rome, pp. 18-29, 2010.

[2] Li, W.H., Degradation and restoration of forest ecosystems in China. Forest Ecology and Management, 201, pp. 33-41, 2004. doi: http://dx.doi.org/10.1016/j.foreco.2004.06.010

[3] Wang, G., Innes, J.L., Lei, J., Dai, S.Y. \& Wu, S.W., China's forestry reforms. Science, 318, pp. 1556-1557, 2008. doi: http://dx.doi.org/10.1126/science.1147247

[4] Wang, G., Innes, J.L., Wu, S.W. \& Dai, S., Towards a new paradigm: the development of China's forestry in the 21st century. International Forestry Review, 10(4), pp. 619-631, 2008. doi: http://dx.doi.org/10.1505/ifor.10.4.619

[5] Liu, J., China's road to sustainability. Science, 328, p. 50, 2010. doi: http://dx.doi.org/10.1126/ science. 1186234

[6] Guan, L.X., Sun, G. \& Cao, S.X., China's bureaucracy hinders environment recovery. AMBIO, 40, pp. 96-99, 2011. doi: http://dx.doi.org/10.1007/s13280-010-0112-6

[7] Li, H.M., Aide, T.M., Ma, Y.X., Liu, W. \& Cao, M., Demand for rubber is causing the loss of high diversity rain forest in SW China. Biodiversity and Conservation, 16, pp. 1731-1745, 2007. doi: http://dx.doi.org/10.1007/s10531-006-9052-7

[8] Cao, S.X., Chen, L., Shankman, D., Wang, C.M., Wang, X.B. \& Zhan, H., Excessive reliance on afforestation in China's arid and semi-arid regions: lessons in ecological restoration. EarthScience Review, 104, pp. 240-245, 2011. doi: http://dx.doi.org/10.1016/j.earscirev.2010.11.002

[9] Cao, S.X., Tian, T., Li, C., Dong, X.B., Yu, X.X. \& Wang, G.S., Damage caused to the environment by reforestation policies in arid and semi-arid areas of China. AMBIO, 39, pp. 279-283, 2010. doi: http://dx.doi.org/10.1007/s13280-010-0038-Z

[10] Gao, G.L., Ding, G.D., Wang, H.Y., Zang, Y.T. \& Liang, W.J., China needs forest management rather than reforestation for carbon sequestration. Environmental Science Technology, 45, pp. 10292-10293, 2011. doi: http://dx.doi.org/10.1021/es203897f

[11] Gao, G.L., Ding, G.D., Wang, H.Y., Zang, Y.T., Liang, W.J., An, Y. \& He, Y., Short communication. Restoring monoculture plantation using stand spatial structure analysis. Forest Systems, 22(1), pp. 147-151, 2013. doi: http://dx.doi.org/10.5424/fs/2013221-03294 
[12] Pommerening, A., Approaches to quantifying forest structures. Forestry, 75(3), pp. 305-324, 2002. doi: http://dx.doi.org/10.1093/forestry/75.3.305

[13] Pommerening, A., Evaluating structural indices by reversing forest structural analysis. Forest Ecology and Management, 224, pp. 266-277, 2006. doi: http://dx.doi.org/10.1016/j.foreco.2005.12.039

[14] Aguirre, O., Hui, G.Y., Gadow, K. \& Jiménez J., An analysis of spatial forest structure using neighbourhood-based variables. Forest Ecology and Management, 183, pp. 137-145, 2003. doi: http://dx.doi.org/10.1016/S0378-1127(03)00102-6

[15] Hui, G.Y., Albert, M. \& Gadow, K., The diameter dominance as a parameter for simulating forest structure. Forstwissenschaftliches Centralblatt, 117, pp. 258-266, 1998. doi: http://dx.doi. org/10.1007/BF02832980

[16] Hui, G.Y. \& Gadow, K. The uniform angle index: derivation of the optimal standard angle. Allgemeine Forst und Jagdzeitung, 173, pp. 173-177, 2002.

[17] Mansourian, S., Dudley, N. \& Vallauri, D., Forest Restoration in Landscapes: Beyond Planting Trees, Springer-Verlag: New York, pp. 8-17, 2005. doi: http://dx.doi.org/10.1007/0-38729112-1 2

[18] Xu, J.C., China's new forests aren't as green as they seem. Nature, 47(7365), p. 370, 2011. 